Simón Henao

Universidad Nacional de La Plata-CONICET

simon.henao@gmail.com

Alba L. Delgado

Universidad de Buenos Aires

albaeledelgado@gmail.com

\title{
El banano, signo de la duración. Patrón, variación y extensión de un fruto
}

\section{The Banana, Sign of Duration. Pattern, Variation and Extension of a Fruit}

\section{Resumen}

En este trabajo nos proponemos estudiar el banano problematizando el exotismo, la mitificación, la fetichización y el cientificismo propio de la mirada colonial. Para ello abordamos la obra Musa paradisiaca, videoinstalación del artista José Alejandro Restrepo, y el diálogo que sostiene con el texto "Volver a comer del árbol de la ciencia" del escritor Juan Cárdenas. Nuestra hipótesis principal es que en la articulación de estas obras la imagen del banano deviene signo de la duración. Como expresión de multiplicidades, contradicciones y heterogeneidades de los tiempos, la duración se expresa en los modos de la presencia de un patrón (que para el caso de nuestro estudio es el banano) que se desliga de lo meramente común y estático y expresa una múltiple, contradictoria y heterogénea presencia que configura variaciones desplegadas en la extensión de los tiempos. La inscripción del banano como patrón conlleva un salirse de contexto, una búsqueda de los resquicios donde se produce el desarreglo de lo dominante y de lo normado, esto es, una variación.

Palabras claves banano; duración; literatura colombiana; arte colombiano; violencias.

\section{Abstract}

In this paper we propose to study the banana by problematizing the exoticism, mythification, fetishization and scientism of the colonial view. To do this, we approach the work Musa 
paradisiaca, a video installation by the artist José Alejandro Restrepo, and the dialogue that it holds with the text "Volver a comer del árbol de la ciencia" by Juan Cárdenas. Our main hypothesis is that in the articulation of these works the image of the banana becomes a sign of duration. As an expression of multiplicities, contradictions and heterogeneities of times, the duration is expressed in the modes of presence of a pattern (which in the case of our study is the banana) that is detached from the merely common and static and expresses a multiple, contradictory and heterogeneous presence that configures variations displayed in the extension of time. The inscription of banana as a pattern entails a departure from context, a search for the gaps where the disorder of the dominant and the norm occurs, that is, a variation.

Keywords Banana; Duration; Colombian literature; Colombian art; Violences.

En últimas, ¿con qué sueñan los racimos de la Musa Paradisiaca? Juan Cárdenas

\section{El banano, signo de la duración}

Al comienzo de Genèse d'un repas, una película documental dirigida por Luc Moullet que se estrenó en Francia en 1979, aparecen Moullet y Antonietta Pizzorno desayunando bananos, huevos y atún. Durante las escenas de este desayuno y a lo largo de la primera secuencia la voz en off del realizador se pregunta, como deja sospechar el título del film, de dónde y a través de qué peripecias llegan esas comidas a su ciudad, quién las produce, cómo lo hacen, cuánto ganan quienes trabajan en ello. La serie de preguntas, con el característico humor cahierista de Moullet, "socarrón y con frecuencia grosero" al decir de Jonathan Rosenbaum (69), embarca a los protagonistas en una larga travesía por Senegal y Ecuador buscando, reportando y testimoniando los pormenores de la cadena productiva que va desde los cultivos en el territorio suramericano o la pesca y enlatado en las costas africanas hasta los comercios parisinos y el consumo en los pequeños departamentos de París, así como las ramificaciones económicas y políticas de todo el proceso, con lo que Genèse d'un repas se convierte en "una de 
las primeras películas en demostrar la explotación al hemisferio sur por parte del hemisferio norte" (Moullet s/p). ${ }^{1}$

Reseñamos la película de Moullet porque, hace unos meses, tras ver una copia recientemente editada, nos picó, como se dice, la curiosidad por el banano y sus representaciones. El objetivo que trajo consigo esta picazón fue el de indagar de qué manera el banano, ese fruto mítico y delicioso, se había convertido en un símbolo, en un objeto legible que, a través de los tiempos, ha sido leído de diversas formas y con distintos niveles de mediación lectora.

Muy sugerente resulta, a propósito de esta diversidad de lecturas y de legibilidades del banano y de todas las variantes que en su mediación existen, lo que sucedió a fines de 2019 cuando se hizo penosamente viral -que no célebre- la escultura que Maurizio Cattelan presentó en el Art Basel Miami de ese año titulada Comedian en la que, con un pedazo de cinta adhesiva plateada, pegó un banano a una pared blanca, atrayendo (¿quién lo hubiera pensado?) todos los focos de la prensa mediática. ${ }^{2}$ Con mucha pena también se hizo viral -que no célebre, insistimos- la intervención performática de David Datuna Un artista hambriento en la que un "artista se come el concepto de otro artista", como dice el propio Datuna frente a las cámaras del diario El país (s/p). En este caso el concepto digerido es el banano de Cattelan valorado en $\$ 120.000$ dólares, según relatan medios como France 24 o The Art Newspaper, donde se informa que "la primera edición del

\footnotetext{
${ }^{1}$ La traducción es nuestra. El artículo que citamos de Rosenbaum fue publicado originalmente en 1977, por lo que no tiene en cuenta la película en cuestión. Pero sí advierte el enfoque crítico del humor con que Moullet, en sus películas previas, como Les contrabandières (1968) o Une aventure de Billy the Kid (1970), encara los distintos temas que aborda. "A la recherche de Luc Moullet: veinticinco proposiciones" está recogido en el libro Adiós al cine, bienvenida la cinefilia.

${ }^{2}$ La escultura de Cattelan se ubica en las antípodas de la bioescultura pública que en el 2009 hizo el artista mexicano Héctor Zamora cuando con su obra Delirio atópico intervino el espacio llenando de enormes racimos de plátanos dos apartamentos hasta desbordar por los ventanales que dan a la Avenida Jiménez en el transitado centro de Bogotá. Con el paso de los días los frutos pasaron de verdes a maduros creando "una pintura viva que va cambiando de color" (El tiempo $\mathrm{s} / \mathrm{p}$ ). Para hacerse una idea de esta intervención pública véase el video del montaje en https://www.youtube.com/watch?v=Rj2UyNJepr4
} 
banano fue vendido a la 1:15am. La segunda se vendió a las 3:30 pm y estamos pensando en una tercera edición para un museo". 3

Contra el uso del banano como chiste de feria y objeto de entretenimiento; contra la ecumenización del banano como símbolo insustancial de la mercancia globalizada propia de la conversión del arte contemporáneo en "delegado [y sustituto] de la comunidad global" (Steyerl 113, 125) y en actor privilegiado de lo que Fisher denomina "realismo capitalista" (40); ${ }^{4}$ contra el empleo del banano, y de su dimensión mítica, como bandera casi arquetípica de la condición transitoria y efímera de la productividad en la sociedad de consumo tecnologizada; contra esto, nuestro enfoque, paradójicamente mucho más simple y analógico que el banano mismo, que el hambre y que la plateada cinta adhesiva del travieso combo frutimediático Cattelan/Datuna, apunta a señalar e identificar ciertas modulaciones de la función simbólica del banano que hacen de él un signo de la duración. ${ }^{5}$

${ }^{3}$ La traducción es nuestra. Véase https:/www.france24.com/es/20191209-art-basel-miami-artistase-come-la-banana-pegada-con-cinta-avaluada-en-150-000- $\mathrm{d} \% \mathrm{C} 3 \% \mathrm{~B} 3$ lares. Véase también https:/www.theartnewspaper.com/news/this-art-is-bananas-maurizio-cattelan-presents-firstnew-work-for-an-art-fair-in-15-years

${ }^{4}$ Dice Fisher que "el realismo capitalista no puede limitarse al arte o al modo casi propagandístico en el que funciona la publicidad. Es algo más parecido a una atmósfera general que condiciona no solo la producción de cultura, sino también la regulación del trabajo y la educación, y que actúa como una barrera invisible que impide el pensamiento y la acción genuinos" (41).

5 Señal de estos usos contra los que acá argumentamos es lo que dice la seguidilla de artículos publicados en el portal ArtNet durante la segunda semana de diciembre refiriéndose al banano como el tópico más discutido en el mundo del arte durante el 2019, por ejemplo en https://news.artnet.com/market/art-basel-maurizio-cattelan-banana-memes-1726233. Acerca de la dimensión mítica del banano conviene por el momento advertir que Roland Barthes, ya en la década del setenta del siglo pasado releyendo sus Mythologies de los cincuentas y afirmando que el mito contemporáneo se enuncia en forma de discurso y por eso depende de una semiología (justamente Barthes en "La mitología hoy" apunta a crear una "nueva" semiología, una "nueva" mitología), señalaba que el mito es legible en la prensa, en la publicidad y en los objetos de consumo de masa, dentro de los cuales, claramente, puede agregarse el banano. El Barthes semiólogo caracteriza esa legibilidad del mito como una "determinación social, un reflejo" ("La mitología hoy" 79). En esta misma lógica "reflexiva" puede ser pensado el uso simbólico del banano aplicado en la publicidad de la multinacional Chiquita Brands International en la ciudad de Londres durante el 2018. No contentos con cubrir los famosos ómnibus de dos pisos de amarillo con enormes calcos que le daban a los automotores las formas del fruto mítico con la leyenda "We are bananas" transitando toda la ciudad, según informa el portal Marketing Directo, durante la campaña publicitaria los bananos fueron aceptados como forma de pago de los icónicos black cabs londinenses. A esta operación, que permitió que miles de pasajeros viajaran en los taxis a cambio de bananos de la marca, se la llamó, simbólicamente, "banana payment". Véase https:/www.marketingdirecto.com/marketing-general/publicidad/ingeniosa-campana-taxispagan-banana-mano 
Dicho de otro modo, el foco de este análisis estará en aquello que el banano presenta y los modos de esa presencia (aquello que el banano da a ver), por sobre aquello que el banano representa (aquello de lo que el banano hace las veces de). Como se verá a lo largo de este trabajo, en el que estudiamos el diálogo y la articulación entre la obra del videoartista José Alejandro Restrepo con la del escritor Juan Cárdenas, al salir de la lógica de la representación, de la sustitución y de la delegación -procesos que, por lo demás y hasta cierto punto, presuponen una dimensión estática del signo y de su función simbólica- y adentrarse, por oposición, en la lógica de la duración como forma de construcción de la temporalidad, se manifiesta, tanto en Musa paradisiaca de José Alejandro Restrepo como en "Volver a comer del árbol de la ciencia" de Juan Cárdenas, la configuración de un proceso dinámico que atraviesa diferentes niveles de patrón, variación y extensión.

Como expresión de multiplicidades, contradicciones y heterogeneidades de los tiempos — cualidades propias de la duración según Braudel (p. 62)—, la duración se expresa en los modos de la presencia de un patrón (para el caso de nuestro estudio el banano) que se desliga de lo meramente común y estático y expresa una múltiple, contradictoria y heterogénea presencia que configura variaciones desplegadas en la extensión de los tiempos. Ya no es solamente la duración bergsoniana que entiende el pasado no solo como tal sino también (y más que nada) como presente, como ese "inaprensible progreso del pasado que descarna el porvenir" (Bergson 242), sino, sobre ello, se trata de comprender la duración en diferentes gradaciones de su intensidad identificadas en las categorías de patrón, variación y extensión. En ese sentido, podemos afirmar que el proceso dinámico con que se construye el banano en las obras de Restrepo y de Cárdenas como signo de la duración no es representacional, puesto que el signo no sustituye al referente; es material, ya que el objeto da a ver aquello que connota: con el banano (esta es la hipótesis) se materializa la duración.

La condición dinámica del proceso, que ha sido organizada en tres instancias correlativas y simultáneas (patrón, variación y extensión) es la que habilita a pensar el banano como signo de la duración. ¿Cómo leer, entonces, el 
banano en el siglo XXI?, ¿qué es lo que el banano presenta cuando está presente?, ¿qué lenguajes, qué lenguas, qué códigos enuncia el banano en su dar a ver la duración? Para poder plantear estas preguntas e hilvanarlas en una serie coherente fue necesario, tras haber visto la película de Moullet que dio origen a la picazón bananera de nuestra curiosidad, pensar el banano (lo que equivale a tomarlo, comerlo y digerirlo) como imagen, esto es, entregarse al ejercicio crítico de realizar una observación imaginaria del banano. En un artículo publicado originalmente en 1986 donde se pregunta ¿qué es una imagen?, Mitchell percibía, de manera crítica, que en los estudios actuales las imágenes son entendidas como formas del lenguaje, como "un tipo de signo que presenta una apariencia engañosa de naturalidad y transparencia, y que oculta un mecanismo de representación opaco [...] un proceso de mistificación ideológica" (109). Y más adelante advierte:

Las imágenes no son solo un tipo especial de signo, sino algo similar a un actor en el escenario de la historia, una presencia o un personaje imbuido de un carácter legendario, una historia paralela que participa de los relatos que nos contamos sobre nuestra propia evolución, desde criaturas "hechas a imagen y semejanza" de un creador a criaturas que se hacen a sí mismas y a su mundo según su propia imagen. (109)

Ya hacia el final del ensayo Mitchell se detiene a estudiar la relación entre las imágenes y las palabras y apunta que "la imagen es el signo que finge no ser signo, enmascarado [...] bajo una inmediatez y una presencia natural" (151. Sin cursivas en el original).

Nos proponemos pensar el banano no como algo inmóvil ni arquetípico sino, por el contrario, como imagen dinámica o nómada que, en su dinamismo, es constitutiva de la historia. En este sentido, la imagen con la que se pretende pensar el banano coincide con un perfil móvil, 
una imagen-movimiento cargada en cuanto que tal de una tensión dinámica $[\mathrm{sic}]$. [...] Es una carga de este género la que Benjamin veía en aquello que llamaba imagen dialéctica y que según él era el elemento mismo de la experiencia histórica. La experiencia histórica se hace a través de la imagen, y las imágenes están ellas mismas cargadas de historia. (Agamben s/p)

\section{Dimensiones críticas de la imagen}

A partir de este gesto, de naturaleza parafrásica, buscamos trazar un corpus (en movimiento) que, en la limitación propia de todo trazado, nos permitiera explorar algunos de los modos con que el banano ha devenido signo de la duración. ${ }^{6}$ La primera imagen de ese trazado provino de la presentación de la videoinstalación Musa paradisiaca en el 2016 en la sala de proyectos de FLORA ars+natura en Bogotá. ${ }^{7}$ Allí, junto a una serie inédita titulada Amanita muscaria, fue expuesta una vez más, de manera conmemorativa, la obra que José Alejandro Restrepo había realizado originalmente en 1996. El curador José Roca describe de esta manera la instalación y sus efectos:

Musa paradisiaca consiste en un recinto en penumbra de cuyo techo penden, como cuerpos, inmensos racimos de plátano hartón; algunos de

\footnotetext{
${ }^{6}$ Hablamos de gesto parafrásico en el sentido que Jacques Rancière le otorga a la paráfrasis cuando apunta, en relación a la escritura como forma general del trabajo del pensamiento, que se trata de "escribir sobre algo que ya está escrito, de inscribirse en el prolongamiento de energías ya trazadas, ya en acto, pero en un modo de actualidad siempre susceptible de engendrar potencias nuevas y de estar elevado a potencialidades nuevas" ("La paráfrasis" 233).

${ }^{7}$ Musa paradisiaca es el nombre de plantas herbáceas del género Musa que fue clasificada por Linneo en 1753 en su Species plantarum. En el sistema de interdependencias con que Humboldt desarrolla su geografía de las plantas (Gómez y Sanz 36) aparecen identificadas las musáceas, dentro de las cuales el banano es un ejemplo, como especies dominantes por su fisonomía en la zona tropical, junto a las palmeras y las canáceas (Castrillón 153). El banano, la banana, el guineo y el plátano son nombres comunes que se le dan a este tipo de plantas y a la variedad de sus frutos por lo que, a efectos de pensarlos como imagen, pueden ser tenidos como sinónimos.
} 
ellos llevan en la punta de su flor-glande un monitor de video que muestra imágenes violentas tomadas de noticieros nacionales sobre las masacres cometidas en las zonas bananeras del país. El espectador, inmerso en el espacio, deambula midiendo con su cuerpo los racimos, oliendo los plátanos en descomposición y mirando, sobrecogido, las imágenes reflejadas en espejos circulares situados en el piso. Con el tiempo los plátanos van cayendo, dejando solo las estructuras mustias de los racimos que recuerdan columnas vertebrales. (147)

Restrepo presenta al banano como agente crítico del relato del poder (Acosta; Arcos-Palma; Gutiérrez; La Ferla; Pini) con la gramática de relaciones entre objetos reales o virtuales y las tensiones temporales (Gutiérrez 95) que ponen en situación en un mismo espacio, reconociendo el mito como un aparato de visión y en él la dimensión mítica del banano imaginado como fruto paradisiaco, el imaginario colonial europeo sobre el trópico, las violencias estatales y la violencia paramilitar. El banano en esta videoinstalación es lo que permite suponer que su imagen, en tanto materialidad crítica, en tanto presencia en un espacio, en su propia presencia producida por el montaje, es un desvío del relato del poder, una sublevación, ese gesto sin fin, como lo caracteriza Didi-Huberman, un desvío que, en términos generales, supone conjugar ética y estética (8).

Los objetos puestos en relación en la gramática de la videoinstalación de Restrepo incluyen el grabado "Musa paradisiaca", una ilustración que hace parte del Viaje a Nueva Granada de Charles Saffray donde aparece una forma de representación del banano como fruto exótico, mítico y paradisíaco propio de la mirada colonial del viajero europeo sobre el territorio americano. En múltiples ocasiones Restrepo ha mencionado que este grabado fue el origen de su Musa. En entrevista con Gutiérrez dice: "Todo comenzó con un grabado del siglo XIX que encontré en el Voyage de la Nouvelle Grenade de Charles Saffray que me pareció absolutamente revelador [...]. Pensé que el título era una alegoría a la musa y al 
paraíso, a toda esa connotación de exhuberancia sexual [...]” (Gutiérrez, "Entrevista" 98).

Acerca de la representación de la naturaleza y la geografía americana en los textos y grabados de Saffray señala Muñoz que se trata de "objetos imperiales", imágenes que no transmitían ningún mensaje neutral "sino que, junto con la parte escrita, adelantaba una percepción y una interpretación del entorno que buscaba integrarlo al sistema económico europeo. En este sentido, lejos de ser o bien un 'reflejo de la realidad', o simplemente una representación, las imágenes planteaban una manera de ver el entorno acorde con los intereses de las dinámicas de expansión europea del siglo XIX” (171. Cursivas en el original). Esa mirada del viajero, codificada de acuerdo a sus intereses, convierte a la naturaleza en un mero producto, "una mercancía lista para ser integrada a los circuitos mercantiles trasatlánticos" (186).

El viaje de Saffray, realizado en 1861, fue publicado en 1872 por Le Tour du Monde: nouveau journal de voyages (Melo 27). Allí Saffray escribió que

[e]n aquel país tan favorecido la tierra es, me atreveré a decirlo así, demasiado generosa, puesto que su fecundidad retarda el progreso. El cultivo inteligente y laborioso impuesto a Europa, no es allí necesario, gracias a la riqueza del suelo y a la benignidad del clima; basta que el hombre trabaje unos pocos días para asegurar la subsistencia de un año. (217)

El grabado ilustra lo éxotico, mítico y paradisíaco resaltado por el cuerpo voluminoso de una mulata de piernas cruzadas que, bajo un frondoso platanal, mira seductoramente hacia un costado. De ahí que, desde un comienzo, Restrepo identifica la idea de asociar la planta con el imaginario colonial de la mirada sobre 
el trópico "donde se mezclan exuberancia sexual y exuberancia natural" (Restrepo 17)..$^{8}$

Pero el grabado de Saffray no es el único documento de archivo que sirve como sustrato a la videoinstalación de Restrepo. El acervo compuesto por una serie de recortes de periódicos, fotografías, fragmentos de noticieros de televisión, documentos oficiales e imágenes publicitarias vinculadas a la producción, circulación y comercialización del banano, así como el foco sobre las violencias estatales y paraestatales vinculadas con la producción y explotación del fruto, hacen parte de la gramática de relaciones con las que Restrepo desmitifica el banano y descompone la ilusoria continuidad del relato dominante. ${ }^{9}$ Se trata de imágenes que, en sus vínculos, aparecen no como relatos sino como hechos, como aquello que está pasando. El uso del archivo, en este caso, no presupone el tiempo de la representación sino que lo suspende. A medida que se ponen en relación los objetos que componen Musa paradisiaca se despliega y desplaza el sentido no tanto como un reenfoque sobre una temporalidad predeterminada por una secuencialidad lineal que el relato colonial acompañó sino en una dimensión de lo temporal acumulado.

\footnotetext{
${ }^{8}$ A propósito de la mirada exotista con la que la literatura de viajes y exploración colonial europea "produ[ce] el resto del mundo" (Pratt 23) y la preocupación por las relaciones entre esta literatura, sus imaginarios y los procesos de la expansión económica europea, remitimos al clásico estudio de Mary Louise Pratt Ojos imperiales. Literaturas de viajes y transculturación, particularmente a su segunda parte, "La reinvención de América, 1800-1850", donde, enfocada en una crítica de la ideología, la investigadora norteamericana indaga acerca de los modos de recepción y apropiación de la representación metropolitana en la periferia durante la primera mitad del XIX. Para Pratt, el final de la dominación española supuso una resignificación de la forma en que Europa veía a América y viceversa. Esta reinvención, apunta Pratt, "está ligada a las vastas posibilidades expansionistas para los capitales, la tecnología, las mercancías y los sistemas de conocimiento europeo" (199) y tuvo en Humboldt - a quien, entre otros viajeros, es dedicado un apartado de Ojos imperiales - , con sus vistas de la naturaleza y su geografía de las plantas, uno de sus principales actores: "[...] fue indudablemente la imagen de la naturaleza virgen elaborada en sus obras científicas y en sus Vistas la que terminó por codificarse en el imaginario europeo como la nueva ideología del "nuevo continente" (223). En cuanto a una lectura de la transculturación vinculada a la obra de Restrepo y sus obras provenientes de la lectura de Humboldt véase de Pini su "José Alejandro Restrepo, cuestionando relatos: de El cocodrilo de Humboldt no es el cocodrilo de Hegel a Iconomía".

${ }^{9}$ Respecto a las violencias de Estado y su relación con la huelga y la masacre de 1928 véase Castrillón; Arango y Vega. Remitimos también a White y a LeGrand. Véase además el libro editado por Archila y Torres. Sobre los vínculos de la violencia paramilitar y las empresas bananeras asociadas a la zona del Úraba se pueden consultar los documentos desclasificados de la National Security Archive (Evans) y el texto de Ortiz, entre otros.
} 
Se trata de una suspensión del tiempo de la representación donde se acumula, en un vínculo relacional, la materia de la historia.

El archivo, con su apariencia casuística, organiza un antes y un después para crear un espacio de planos discontinuos cuya materialidad concibe, hace presente e intensifica otra de las formas posibles de la duración, aquella donde se produce en tiempo y espacio la discontinuidad de lo mismo. Este proceso dinámico de la duración como ruptura del trayecto hacia el instante de la representación desplaza el banano de un tiempo a otro, aún cuando ese tiempo insista en una suerte de permanencia inmóvil: la insistencia es la inscripción; la inscripción es el patrón.

La insistencia como fenómeno de ruptura pone en tensión la representación propia del relato dominante y la presentación como expresión de la obra. El banano en la representación expresa el proceso mediante el cual la producción y circulación del fruto sufre una fetichización como mercancía. Por su parte, el banano de Restrepo en su insistencia, inscribe su desmitificación al presentarlo como parte de un proceso de producción en donde ya no hay una representación de lo exótico cuya relación con el fruto oculta su carácter de mercancía, sino una inscripción del banano como proceso de producción de la violencia, es decir, una presentación del banano como signo de la duración. De ahí que Musa paradisiaca sea una experiencia crítica dentro del arte colombiano.

\section{La imagen desfasada o aparición de la masa sonora}

La segunda imagen con la que nos topamos en el trazado de un corpus que diera cuenta de los modos en que el banano ha devenido signo de la duración hace parte de otro artefacto compuesto de una gramática de relaciones, en este caso literarias. Se trata del libro Volver a comer del árbol de la ciencia de Juan Cárdenas, publicado en 2018 y en cuya portada - e insistentemente en su contratapaaparece un recorte de la acuarela "Musa Paradisiaca, Bananier cultivé", publicada en 1816 por el famoso pintor de plantas Pierre-Joseph Redouté en el octavo tomo 
de su imponente obra Les liliaceés, en la que se ven las grandes hojas de la planta con un racimo de frutos aún verdes que pende frondoso con una flor en su punta (Redouté 144). El libro de Cárdenas reúne textos de diversa procedencia y de marcada heterogeneidad. Allí coexisten cuentos como "Encomendar el alma", "El pájaro" o "Calibán" con notas de lectura sobre Felisberto Hernández o textos programáticos como "Nudos ciegos". Hay también textos híbridos entre los que se encuentra el que le da título al volumen, un escrito que originalmente el autor payanés había publicado dentro del catálogo de la exposición conmemorativa de la instalación Musa paradisiaca en 2016 de José Alejandro Restrepo, "a quien le debo", aclara Cárdenas en "Nota sobre los textos", "muchos de los métodos asociativos y procedimientos empleados en este libro" (Volver 175).

En efecto, "Volver a comer del árbol de la ciencia" está compuesto de una compleja red de evocaciones, referencias y relatos vinculados a experiencias de lo sensible que ponen en juego los sentidos en función de los signos. Mediante estas asociaciones y procedimientos Cárdenas practica lo que él mismo arenga en "Nudos ciegos" donde señala la existencia de un "enfrentamiento hipotético [que] nos permite apreciar el carácter absolutamente visual de nuestra escritura" (Volver 170).

Ese enfrentamiento es lo que lleva a que lo visual, por medio de imágenes, se integre a la narración, no decorándola ni ambientándola sino conformándola, de manera tal que la representación se imponga a lo representado, algo que es característico de la escritura de Cárdenas, así como lo es en la obra de Restrepo, en la que, con marcada insistencia, se da a ver el proceso que la produjo y en la que permentemente son expuestas sus formas de representar.

Jacques Aumont, respecto de la imagen y lo visual, advierte que no todas las imágenes tienen una forma visual y lo visual es una modalidad particular de la imagen general. Es significativo cómo en "Nudos ciegos" el propio Cárdenas vincula la escritura con lo visual al señalar que al mirar una imagen no hacemos algo muy distinto a lo que hacemos al leer: "Vamos removiendo capas, una detrás de otra, hasta que comprobamos que la imagen alude a otras imágenes y, casi de inmediato, como si quisiera dejar de ser imagen, la imagen se desborda hacia los 
márgenes de la percepción y de la memoria. La imagen también quiere volverse sonido, quiere volverse olor y, en últimas, quiere volverse palabra" (Volver 172).

En las novelas Los estratos, publicada en el 2013, Ornamento, del 2015 y El diablo de las provincias del 2017, a través del registro de la heterogeneidad del lenguaje, la literatura se ofrece como forma de la crítica, como construcción inteligible del presente (Barthes “¿Qué es la crítica?” 352). Cárdenas habla de una serie de procedimientos utilizados "para que las voces de distintas procedencias se entremezclen y creen una especie de masa sonora" (Rincón $\mathrm{s} / \mathrm{p}$ ). Es en la articulación de esa masa sonora donde ésta literatura encuentra su forma de salir de sí misma, de dar a ver una imagen desfasada de lo literario o, como quería Deleuze, su forma de escapar del sistema dominante, su devenir-otro de la lengua ("La literatura y la vida" 16), su forma de poner la lengua en desequilibrio ("Balbució" 151). Ese es, para decirlo de otra forma, el deseo crítico con el que la escritura de Cárdenas se hace radicalmente literaria.

En un artículo de 1982 Ana María Barrenechea plantea la existencia de dos tendencias contrapuestas, no clasificatorias, en la relación entre literatura y referente, una que lo anula (ejemplificada por una novela de Salvador Elizondo) y otra que lo postula "rabiosamente" (como en el caso de El zorro de arriba y el zorro de abajo de Arguedas). La ruptura del contrato mimético, acota la crítica, "bloquea el proceso de reconocimiento y de lectura en el que la obra remite al mundo y el mundo a la obra. Entonces se fuerza a leer el texto como un objeto verbal autónomo" (378). Y más adelante agrega:

Ante la crisis del contrato mimético, los escritores pueden inclinarse a la antirreferencialidad o bien decidirse por una suprarreferencialidad que, cuestionando la mímesis novecentista y la confianza que su realismo tenía en las relaciones lenguaje-literatura-mundo, no abandona el diálogo con el referente, sino que lo realza hasta exasperarlo. (381) 
Más allá del esquematismo didáctico de Barrenechea habría que situar la narrativa de Cárdenas en otro lugar, allí por donde han transitado Felisberto Hernández y César Aira; allí donde, permanentemente, es expuesta la tensión que produce la fuerza ejercida por el referente (el aquí y ahora de la enunciación) y el entretejido sígnico de su abstracción. Situarla, entonces, en un ir y venir de la referencialidad, un aparecer y desaparecer, a través de la masa sonora, del referente.

Es llamativo el caso de la novela Ornamento pues allí el proceso de destrucción de la dimensión representativa de lo literario se produce, paradójicamente, a través de un exceso de mímesis o, mejor aún, del uso de la mímesis como exceso y del exceso como forma de ruptura con el contrato mimético, que lleva al médico narrador de la novela a asumir que "[n]ada sobra, en realidad. No hay nada que sea estrictamente decorativo o superfluo. Todo sirve para algo, en la medida en que nada sirve para nada" (Cárdenas, Ornamento 68).

La asimilación del desfasaje de la imagen hace que en esta novela, y en general en la escritura de Cárdenas, la representación funcione como una tecnología que reordena lo sensible, como estupefaciente, como una perturbación de lo sensible y se constituya en sujeto de representación, en efecto de su propio sistema de representación, en ornamento, esto es, en una mera relación entre signos.

Es esta relación entre signos la que en "Volver a comer del árbol de la ciencia" da forma a una escritura claramente heterogénea. Se trata de una escritura despojada del género y despojada del marco; una escritura que estalla a raíz de la fuerza investida por los métodos asociativos; por el montaje si lo entendemos como "práctica de juntar cosas que no van juntas o que no parecen ir juntas o que incluso todavía no se han visto ir juntas" (Rancière, "El momento de la danza" 81); por la pura conexión de sus partes y por los procedimientos empleados que implican la coexistencia de diversos niveles de la discursividad en los que intervienen Bradshaw, el gerente de la United Fruit Company durante los hechos de la masacre de las bananeras en 1928; el chachachá "La banana" de Ben et sa Tumba; un ingeniero agrónomo que imagina ser esclavizado por los bananos; Heinrich von Kleist y sus reflexiones sobre el movimiento y las marionetas; las relaciones entre 
el banano y el Corán; los experimentos de un grupo de científicos dirigidos por Briujonenko; las clasificaciones de Linneo y sus matices bíblicos; la icónica imagen publicitaria de Chiquita Brands donde aparece un banano seductor disfrazado de Carmen Miranda; las figuras humanoides de los racimos de plátanos; los soldaditos de La casa grande, entre otras cuantas cosas. Es allí, en las indeterminaciones de estas asociaciones, en la estructura compleja de sus conexiones, en las interferencias y condensaciones y en la fuerza que genera el ensamblaje de las partes, y no tanto en el desarrollo de un esquema, donde surge una toma de posición, un posicionamiento crítico que abre la posibilidad (la emergencia de lo posible) de intervenir en el orden y crear, a efecto de esa fuerza, nuevos ordenamientos de lo sensible.

En la literatura de Cárdenas son estas sensibilidades reordenadas las que ponen en escena la diferencia entre, por un lado, el relato como una representación narrativa de sujetos en un tiempo y un espacio cometiendo acciones, esto es, articuladas a través de la sucesión de frases verbales que conllevan una implícita continuidad casuística, y por otro lado el relato o lo literario como un espacio del lenguaje en el que aparece privilegiada la coexistencia, como una fuerza enunciada como conjunto que desencadena efectos críticos sobre lo real. En esta escritura lo literario está dado como un dispositivo enunciativo no representativo, como un ordenamiento del lenguaje que se posiciona como un paradigma de relaciones de frente a la suceción causal del relato y a la representación, encarándola, señalando lo que en ella hay de subordinación con lo real.

Esto es algo que distingue al texto de Cárdenas dentro de la tradición de la literatura bananera a la que podría sumarse "Volver a comer del árbol de la ciencia". Desde el realismo del cuento de Gregorio Castañeda de 1923 "Náugrafos de la tierra", "una historia contada de forma líneal" al decir de Jacques Gilard (25), hasta la imaginería y la humorada de "Si no fuera por la zona caramba", el relato de Ramón Illán Bacca de 1979 o de su novela Maracas en la ópera (1999), pasando por el costumbrismo documentado de Los muertos tienen sed de Javier Auqué Lara (1969), el realismo mágico de Cien años de soledad (1967) e, incluso, a pesar de la 
apuesta disrruptiva de su estructura, el vanguardismo de La casa grande de Cepeda Samudio (1962) o de Soldados (1966), la adaptación teatral que de ella hicieron primero Carlos José Reyes y el Teatro La Candelaria y luego Enrique Buenaventura (Reyes 481), esta literatura bananera está subordinada a la representación y al referente que la habilita. En Cárdenas, por el contrario, se puede advertir que la representación no está tanto subordinada al referente como a las asociaciones, es decir, a la relación de correspondencias entre la compleja red de referentes que estructuran la textualidad. ${ }^{10}$

\section{Indeterminación del tiempo o lo que dura el banano}

El diálogo que sostiene la videoinstalación archivística de Restrepo con la escritura de Cárdenas en "Volver a comer del árbol de la ciencia", como operación crítica, activa un patrón, una extensión y una variación. Así como en la dimensión crítica de Musa paradisiaca la inscripción es el patrón en tanto resultado de la insistencia que presenta al banano como signo de la duración, también en "Volver a comer del árbol de la ciencia" hay una inscripción en el patrón para salir de él y con ello salir del contexto, salir del relato, salir de lo normado. En la articulación y diálogo entre las dos obras los múltiples procedimientos de asociaciones discontinuas generan una imagen desfasada del banano, de su fetichización como mercancía, de su exotismo y de su dimensión mítica y científica, haciendo de él un signo de la duración.

La inscripción del banano como patrón conlleva un salirse de contexto, una búsqueda de los resquicios donde se produce el desarreglo de lo dominante y de lo normado: una variación. Variación frente al exotismo; variación frente a la mitificación; variación frente a la fetichización del fruto como mercancía; variación

\footnotetext{
${ }^{10}$ A propósito de la literatura bananera en Colombia véase de Gilard. Remitimos también al artículo de Pernett.
} 
frente al cientificismo de la mirada colonial extendida en el realismo capitalista. Todas estas variaciones, activadas en el diálogo y la articulación entre las obras, conllevan, también, a irrumpir la aparente armonía del orden, extraer cada una de las piezas, destrozar la unidad, el consenso y el sentido común, para verlas desagregadas en solitario — recordemos: ver equivale a imaginar-, con el fin de reponerlas de otra manera, extenderlas hacia otro lugar, darlas vuelta por fuera de su texto, pisar, como se dice, la cascarita del banano.

En lugar de seguir simplemente el ritmo de la acción, como lo habría hecho normalmente un relato, la escritura de Cárdenas, análogo al procedimiento de Restrepo con las imágenes del archivo heterogéneo, no solo se distancia sino además se inclina hacia un lugar opuesto, un lugar contrario al de las acciones del relato y de la fábula que, como acotó Foucault, "es lo que merece ser dicho" (136). Se trata de un movimiento, de una variación que en su desplazamiento conlleva otro lugar de los hechos, no tanto porque los hechos dejen de serlo (la narración, en todo caso, continúa estando presente y aquello que merece ser dicho es, de todas formas, dicho) sino porque la presencia de esos hechos en el relato se encuentran en otro lugar, allí donde la escritura pisa, indeterminadamente, la cascarita del banano. Ese otro lugar nada tiene que ver con el olvido, más bien todo lo contrario. Es la forma que toma el lenguaje para darle a los hechos la consistencia de la memoria.

Por eso el Volver del título no es otra cosa que una imagen desfasada. Volver no como repetición, no, sino como permanencia; permanencia indeterminada en el tiempo. El infinitivo, que sutilmente impugna la sucesión y el devenir, expresa una acción que hace del presente el tiempo de la enunciación. Volver es, así, un signo gramatical de la duración. Volver a comer designa, con el infinitivo del verbo, una huella que permanentemente orada en el presente. Volver es también la posibilidad del diálogo que Cárdenas establece con Restrepo ya en 1996, cuando todavía "Volver a comer..." era inexistente. Acá, con el banano, el fruto asociado al mito del árbol de la ciencia, volver no es ir hacia atrás, es más un acto de la mordedura y de la masticación dada al presente, un reflejo de la necesidad barthesiana de 
vomitar el estereotipo, un acto digestivo-discursivo que se actualiza siempre y necesariamente en la intensidad de cada enunciación. En la oración del título la acción es el sujeto y al haber ausencia de intervención del enunciador (¿quién habla acá y ahora?) no hay tampoco una especificidad como sí la hay en la modalidad de enunciación histórica que especifica los acontecimientos como pasados. ${ }^{11}$ En el texto de Cárdenas se trata de una voz que enuncia en acto presente pero que remite, en su propio enunciado, a una temporalidad ya transcurrida, ausente en el presente. Este ensamblaje entre pasado y presente, sintetizado en el título y cuyo signo es el banano, puede reconocerse como permanencia, como duración.

Escribir la historia no desde el acontecimiento, aquello que ocurre, sino desde lo que perdura, desde la permanencia. No desde los hechos sino desde los efectos. Una permanencia de lo que dura que, lejos de deberse al misterio, se debe a los restos, a lo que ha sido dejado de lado. Como las balas, ese otro signo de la duración, que en "Encomendar el alma" encuentra el narrador en el cerro La Tetilla, un cerro en el occidente colombiano cercano a Popayán por donde cruzó Humboldt en su exploración al Volcán del Puracé cuando iba para Quito y donde encontró “el basalto más puro y terroso que jamas vi” (Humboldt $\mathrm{s} / \mathrm{p}$ ): balas de las guerras civiles del siglo XIX; balas que "se han venido acumulando desde 1800" (Cárdenas, Volver 13); balas viejas; balas nuevas; balas de todas las edades como indicios geológicos de la duración y que, como bien advierte Rivera, "hablan de una conflagración del pasado y de una destrucción antigua que, sin embargo, no deja de acontecer" (s/p).

\footnotetext{
${ }^{11}$ Aludimos a la distinción que hace Emile Benveniste entre los dos planos de la enunciación, el de la historia y el del discurso, fundamentada en los diferentes tiempos verbales utilizados. La característica principal del plano de la historia es el del borramiento del enunciador, como si la historia se contara por sí sola. Al respecto dice Louis Marin: "La historia se caracteriza por un modo específico de enunciación que consiste en borrar, en excluir las marcas de la enunciación en el enunciado: en la historia, la enunciación no se enuncia. El relato es un discurso con un narrador ausente. Los acontecimientos de la historia parecen narrarse ellos mismos en el relato sin remitir al acto productor del relato. Primera extrañeza: el relato es el discurso menos los signos del discurso. La enunciación histórica, reservada a la lengua escrita, caracteriza el relato de los acontecimientos pasados, es la representación de los hechos acaecidos en cierto momento del tiempo sin ninguna intervención del locutor en el relato" (67. Cursivas en el original).
} 
En esa conflagración y en ese encuentro entre tiempos heterogéneos, contradictorios y múltiples que surge del diálogo entre Musa paradisiaca y "Volver a comer del árbol de la ciencia” se origina la necesidad de acudir a una gramática de relaciones, al procedimiento asociativo y al montaje. De esa forma se reordena lo sensible, se sale de una oficialidad normada de la escritura y de la imagen, aquella normativizada, naturalizada y normalizada en relatos e imágenes, en los modos de ordenar el archivo y de construir la memoria; aquella que los escritores de salón, los artistas de ferias y entretenimiento en ciudades amuralladas ejecutan con brillo y resplandor. Salirse pero no excluirse, mantenerse en los márgenes para desde allí des-mitificar, des-exotizar, des-fetichizar y des-cientifizar el fruto al presentarlo como parte de un proceso de producción de las violencias, como en el hipotético sueño de los racimos de la Musa paradisiaca que flotan por encima de las imágenes de una pesadilla.

\section{Bibliografía}

Acosta, María del Rosario. "Tras los rastros de Macondo: archivo, memoria e historia en Musa paradisiaca de José Alejandro Restrepo". Estudios de Filosofía 58 (2018): 41-64.

Agamben, Giorgio. "El cine de Guy Debord". Cinereverso (2020). https://cinereverso.org/el- cine-de-gut-debord/\#.XhXpYy9UBix. 7 de enero de 2020.

Arango, Carlos. Sobrevivientes de las bananeras. Bogotá: Hego impresores, 1981. Archila, Mauricio y Torres, Leidy (eds.). Bananeras: huelga y masacre 80 años. Bogotá: Universidad Nacional de Colombia, 2009.

Arcos-Palma, Ricardo. "Violencia, imagen y creencia. Reflexión sobre la obra de José Alejandro Restrepo". Ensayos. Historia y teoría del arte 17 (2009): 6-23.

Aumont, Jacques. La imagen. Buenos Aires: Paidós, 2013.

Auqué Lara, Javier. Los muertos tienen sed. Caracas: Monteávila, 1969.

Barrenechea, Ana María. "La crisis del contrato mimético en los textos contemporáneos". Revista Iberoamericana, XLVIII/118-119 (1982): 377-381. 
Barthes, Roland. "La mitología hoy”. El susurro del lenguaje. Madrid: Editora Nacional, 2003. 79-83. . ¿Qué es la crítica?”. Ensayos críticos. Buenos Aires: Seix Barral, 2003. 345-352.

Bergson, Henri. Materia y memoria. Ensayo de la relación del cuerpo con el espíritu. Madrid: Aguilar, 1963.

Braudel, Ferdinand. "La larga duración". La historia y las ciencias sociales. Madrid: Alianza, 1969. 60-106.

Cárdenas, Juan. "Volver a comer del árbol de la ciencia". Musa paradisiaca. José Alejandro Restrepo. Bogotá: Ediciones Flora, 2016. 125-143. . Ornamento. Madrid: Periférica, 2015. . Volver a comer del árbol de la ciencia. Bogotá: Tusquets, 2018.

Castañeda Aragón, Gregorio. "Naúfragos de la tierra". Otros cuentistas. A. A. V. V. Bogotá: Minerva,1936. 67-98.

Castrillón, Alberto. 120 días bajo el terror militar o la huelga de las bananeras (Exposición ante el Congreso). Bogotá: Talleres de la revista Universidad, 1979.

Castrillón Aldana, Alberto. Alejandro de Humboldt, del catálogo al paisaje. Medellín: Universidad de Antioquia, 2000.

Cepeda Samudio, Álvaro. "La casa grande". Obra literaria. Edición crítica. Medellín-Poitiers: Sílaba-Centre de recherches Latino-américainesArchivos, 2017. 98-258.

Deleuze, Gilles. "La literatura y la vida". Crítica y clínica. Barcelona: Anagrama, 1996. 11-18.

. "Balbució". Crítica y clínica. Barcelona: Anagrama, 1996.150-159.

Didi-Huberman, George. "El arte de la vida otra, o como ser gobernado". Chuy. Revista de estudios literarios latinoamerianos 5 (2018): 4-22.

El tiempo. "Colgaron plátanos en dos edificios de la Av. Jiménez; es una obra de un artista mexicano". El tiempo 17 de octubre (2009). www.eltiempo.com/archivo/documento/CMS-6378089 (6/02/20). 6 de febrero de 2019.

El país. "David Datuna defiende su actuación en ArtBasel". El país, 10 de diciembre (2019). https://www.youtube.com/watch?v=a8bQsyjE42o.1 de febrero de 2020.

Evans, Michael. "The Chiquita Papers. Banana Giant's Paramilitary Payoffs Detailed in Trove of Declassified Legal, Financial Documents". The National Security Archive (2011). https://nsarchive2.gwu.edu/NSAEBB/NSAEBB340/. 1 de enero de 2020.

Fisher, Mark. "El capitalismo y lo real". Realismo capitalista. ¿No hay alternativa?. Buenos Aires: Caja negra, 2016. 41-47.

Foucault, Michel. La vida de los hombres infames. La Plata: Altamira, 1996. García Márquez, Gabriel. Cien Años de soledad. Buenos Aires: Debolsillo, 2016. Gilard, Jacques. "La zona bananera". Obra literaria. Edición crítica. Álvaro Cepeda Samudio. Medellín-Poitiers: Sílaba-Centre de recherches Latinoaméricaines- Archivos (2017).www.mshs.univ- 
poitiers.fr/crla/contenidos/Archivos/SITIO/04_BANANERAS/030_Gilar d.pdf. 6 de febrero de 2020 .

Gómez Mendoza, Josefina. y Sanz Herráiz, Concepción. "De la biogeografía al paisaje de Humboldt: pisos de vegetación y paisajes andinos equinocciales". Población \& Sociedad 17 (2010): 29-57.

Gutiérrez, Natalia. “José Alejandro Restrepo". Arte en Colombia Internacional 73 (1998): 64-66.

. "Entrevista con José Alejandro Restrepo". Cruces: una reflexión sobre crítica de arte y la obra de José Alejandro Restrepo. Bogotá: Alcaldía Mayor de Bogotá, 2000. 80-111.

Humboldt, Alejandro de. Alejandro de Humboldt: viaje por Colombia. Extractos de sus diarios. Bogotá: Banco de la República (2000). www.banrepcultural.org/humboldt/home.html. 13 de febrero de 2020 .

Illán Bacca, Ramón. "Si no fuera por la zona caramba". Gato suelto y feliz y otros cuentos, Manizales: Universidad de Caldas, 2012. 127-139.

La Ferla, Jorge. “José Alejandro Restrepo. Tres décadas de creación con el arte y la tecnología". Artelogie 11 (2017). www. journals.openedition.org/artelogie/1531. 25 de enero de 2020.

LeGrand, Catherine. "Living in Macondo. Enconomy and culture in a United Fruit Company. Banana enclave in Colombia". Gilbert Joseph, Catherine LeGrand y Ricardo Salvatore. Close encounters of Empire. Writing the cultural history of U.S-Latin American relations. Durham: Duke University press, 1998. 333-368.

Marin, Louis. Destruir la pintura. Buenos Aires: El fiordo, 2015.

Melo, Jorge Orlando. "La mirada de los franceses: Colombia en los libros de viaje durante el siglo XIX". (2001). www.academia.edu/35137474/La_mirada_de_los_franceses_Colombia en_los_libros_de_viajes_del_siglo_XIX (9/01/20). 9 de enero de 2020.

Mitchell, William John Thomas. “QQué es una imagen?”. Ana García Varas, editora. Filosofía de la imagen. Salamanca: Universidad de Salamanca, 2011. 107-154.

Moullet, Luc y Cronk, Jordan. "Against the Actualité: An Interview with Luc Moullet". Notebook (2019). www.mubi.com/es/notebook/posts/againstthe-actualite-an-interview-with-luc-moullet. 4 de enero de 2020.

Muñoz, Santiago. "Las imágenes de viajeros en el siglo XIX. El caso de los grabados de Charles Saffray sobre Colombia". Historia y grafía 34 (2010): 169-204.

Ortiz, Carlos Miguel. "Procesos sociales y violencia en Colombia: el caso del Úraba". Exclusión social y construcción de lo público en Colombia. Alberto Valencia compilador. Bogotá: CEREC-CIDSE, 2001. 255-264.

Pernett, Nicolás. "Las masacres de las bananeras en la literatura colombiana".. Bananeras: huelga y masacre 80 años. Mauricio Archila y Leidy Torres, editoras. Bogotá: Universidad Nacional de Colombia, 2009. 193-229.

Pini, Ivonne. "José Alejandro Restrepo, cuestionando relatos: de El cocodrilo de Humboldt no es el cocodrilo de Hegel a Iconomía”. Traducir la imagen. 
El arte colombiano en la esfera transcultural. Ivonne Pini y María Clara Bernal. Bogotá: Universidad de los Andes, 2012. 61-90.

Pratt, Mary Louise. Ojos imperiales. Literatura de viajes y transculturación. Quilmes: Universidad de Quilmes, 1997.

. "El momento de la danza". Tiempos modernos. Ensayos sobre la temporalidad en el arte y la política. Santander: Shangrila, 2018. 65-90.

. "La parafrásis". Anacronismo e irrupción 9/17 (2019): 231-237.

Redouté, Pierre-Joseph. Les liliaceés, volume 8. París: Imprenta de Didot Jeune, 1816.

Restrepo, José Alejandro. “Musa paradisiaca”. Musa paradisiaca. Bogotá: Ediciones Flora, 2016. 15-111.

Reyes, Carlos José. Teatro y violencia en dos siglos de historia de Colombia, Tomo II. Bogotá: Ministerio de cultura, 2014.

Rincón, Juan Camilo. "Viaje al exótico mundo de la esgrima con machetes del Cauca". El Tiempo, 2 de diciembre de 2019. www.eltiempo.com/cultura/musica-y-libros/juan-cardenas-lleva-a-suslectores-al-mundo-de-la-esgrima-con-machetes-del-cauca-439288. 3 de diciembre de 2019.

Rivera Garza, Cristina. "Un cerro lleno de balas viejas: una escritura geológica de Juan Cárdenas". Literal, 16 de julio 2019. www. literalmagazine.com/uncerro-lleno-de-balas-viejas-una-escritura-geologica-de-juan-cardenas/. 21 de noviembre de 2019.

Roca, José. "Postfacio". José Alejandro Restrepo. Musa paradisiaca. Bogotá: Ediciones Flora, 2016. 145-153.

Rosenbaum, Jonathan. " $A$ la recherche de Luc Moullet: veinticinco proposiciones". Adiós al cine, bienvenida la cinefilia. La cultura cinematográfica en transición. Buenos Aires: Monte Hermoso, 2018. 6482.

Saffray, Charles. Viaje a Nueva Granada. Bogotá: Biblioteca popular de cultura colombiana, 1948.

Steyerl, Hito. "Arte duty free". Arte duty free. El arte en la era de la guerra civil planetaria. Buenos Aires: Caja Negra, 2018. 109-142.

Vega, Renán. "La masacre bananera de 1928”. Colombia entre la democracia y el imperio. Aproximaciones históricas a la turbulenta vida nacional del siglo XX. Bogotá: El búho-Códice, 1989. 95-132.

. "Balas y bananos en el enclave de la United Fruit Company". Gente muy rebelde. Tomo I: Enclaves, transportes y protestas obreras. Bogotá: Pensamiento crítico, 2002. 265-338.

White, Judith. Historia de una ignominia. Bogotá: Presencia, 1978.

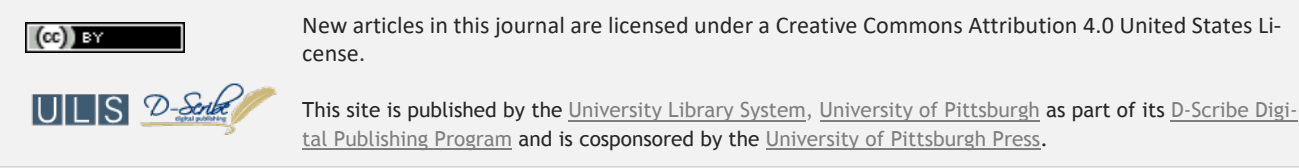

